\title{
Spatial autocorrelation of ovine protein polymorphisms in Europe
}

\author{
JG Ordás, JA Carriedo \\ Departamento de Producción Animal I, Facultad de Veterinaria, \\ Universidad de León, 24071 León, Spain
}

(Received 3 June 1996; accepted 8 October 1996)

\begin{abstract}
Summary - The allelic frequencies of haemoglobin, protein X, arylesterase, transferrin, carbonic anhydrase and albumin in 71 European ovine populations were studied using spatial autocorrelation analysis. Haemoglobin and transferrin show significant clinal patterns. The observed clines may be a result of migrations and genetic drift occurring since the first domestication of ovines.
\end{abstract}

sheep / protein polymorphism / spatial autocorrelation / gene flow

Résumé - Autocorrélation spatiale de polymorphismes protéiques ovins en Europe. Les fréquences des gènes de l'hémoglobine, la protéine $X$, l'arylestérase, la transferrine, l'anhydrase carbonique et l'albumine dans 71 populations ovines européennes ont été soumises à une analyse d'autocorrélation spatiale. L'hémoglobine et la transferrine montrent des structurations spatiales significatives. Les clines observés peuvent être le résultat de migrations et de dérive génétique intervenues depuis la première domestication des ovins.

mouton / polymorphisme protéique / autocorrélation spatiale / flux génique

\section{INTRODUCTION}

Spatial autocorrelation techniques can be used to study the pattern of allelic frequencies among populations in a given area (Sokal and Oden, 1978; Oden, 1984). This type of technique has been used in studies of allelic frequencies in different animal species and humans (eg, Sokal et al, 1980; Easteal, 1985; Barbujani, 1987; Barbujani et al, 1994). Similar studies have not been undertaken on species of domestic animals.

The aim of this study is to analyze the distribution patterns of allelic frequencies of some protein polymorphisms in European ovine populations, by spatial autocorrelation. The description of these patterns could contribute to improving our understanding of the evolutionary processes affecting ovine breeds. 


\section{MATERIALS AND METHODS}

We screened 124 papers published between 1958 and 1994 in 58 journals. Those polymorphisms for which information is not available from a minimum of 30 populations were rejected. The analysis was thus restricted to six loci: haemoglobin beta (HBB), protein X (X), arylesterase (ES), transferrin (TF), carbonic anhydrase (CA) and albumin (ALB) and 71 European ovine populations (fig 1). All the bibliographical sources used employ international allelic nomenclature. A complete list of the data analysed and of the respective bibliographical sources is available from the authors on request.

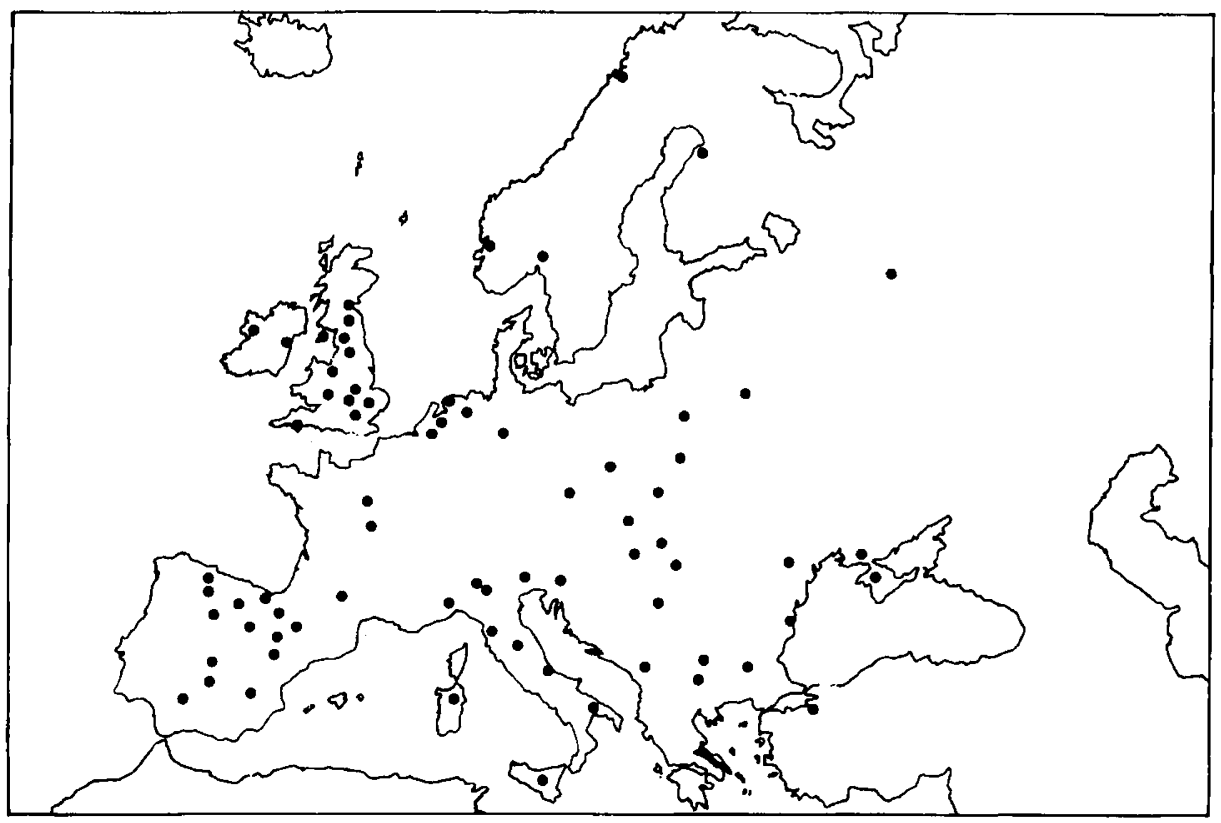

Fig 1. Geographical distribution of the ovine populations analysed.

The numbers of populations and individuals considered were, respectively, 69 and 38840 for HBB, 30 and 8966 for X, 37 and 16442 for ES, 53 and 42162 for TF, 31 and 13088 for CA, and 35 and 12105 for ALB. The populations were assigned to the geographical location indicated by the respective authors. If there were data on two or more flocks in the same location, mean values of allelic frequencies were calculated. Each local population was identified by its latitude and longitude.

Analysis was carried out using the SAAP spatial autocorrelation programme (Wartenberg, 1989) with ten variable classes of distance. The limits of these classes were $434,732,977,1167,1349,1546,1754,2032,2417$ and $3082 \mathrm{~km}$. The autocorrelation coefficient, Gearys's $c$, was computed for each class and allele. The set of autocorrelation coefficients calculated for one allele (correlogram) allows an objective definition of the spatial modes of variation shown by that allele. 
At diallelic loci, that is all except TF, the correlograms of the two alleles are identical. At the TF multiallelic locus the correlograms of alleles $A, B, C$ and $D$ were taken into account. Rare variants of $\mathrm{CA}, \mathrm{ALB}$ and TF were rejected.

\section{RESULTS}

Figure 2 shows the correlograms observed for the six protein polymorphisms. Two groups of correlograms can be differentiated: on the one hand, those for HBB and TFD are statistically significant $(P \leqslant 0.007$ and $P \leqslant 0.001$, respectively); on the other hand, those for $\mathrm{X}, \mathrm{ES}, \mathrm{CA}$ and $\mathrm{ALB}$ and three remaining TF alleles are not significant.

HBB shows significant positive autocorrelations in the short distance classes and significant negative autocorrelations at great distance. In other words, European ovine populations show similar HBB allelic frequencies at distances of less than $977 \mathrm{~km}$, but markedly different ones at distances greater than $2032 \mathrm{~km}$. The HBB autocorrelation coefficients vary in almost monotonic fashion from short to long distances. This variation pattern is defined as a cline (Sokal and Oden, 1978). HBB A allelic frequencies gradually decrease between $68^{\circ}$ and $38^{\circ}$ latitude, that is, from the north to the south of Europe.

The TF D allele is that of highest frequency at the transferrin locus. This allele also shows significant positive autocorrelation in the first distance classes and significant negative autocorrelation in the last classes. The $c$ values for this allele generally increase with distance. Thus the geographical variation pattern for TF $\mathrm{D}$ is also clinal. The flocks with the lowest values for TF D are generally to be found in higher European latitudes, whilst those with high values of this allele are more frequent at the low latitudes. The gradual increase from countries in the north to those in the south of Europe for TF D, as well as HBB B, is corroborated by linear correlation analysis (Ordás and Carriedo, manuscript in preparation).

\section{DISCUSSION}

The sample includes many different breeds each with a certain degree of interbreeding with others, and each with characteristic allele frequencies and geographic distributions. However, the sample is not dominated by one or a few breeds. Consequently, the clines may not be the result of sheep breed structure.

It is possible that HBB A could have some disadvantage in warm regions (Agar et al, 1972). TF D could also suffer from some disadvantage in cold regions. On the other hand, associations between production or reproduction traits and HBB or TF genotypes have been established, but the results obtained are quite different in ovine breeds (eg, Altaif and Dargie, 1978; Morris et al, 1988). Differences in selection pressures, of the order of mutations rates, could be enough to maintain clines (Cavalli-Sforza and Bodmer, 1981). However, it must be pointed out that there is no conclusive proof that HBB and TF ovine polymorphisms have different adaptive values. Because of this the clines found for these loci may not be stable, but rather a transitory result of migrations and genetic drift.

Sheep domestication occurred during the Neolithic period in south-east Asia. Sheep migrated to Europe along two basic routes: an interior one along the Danube 

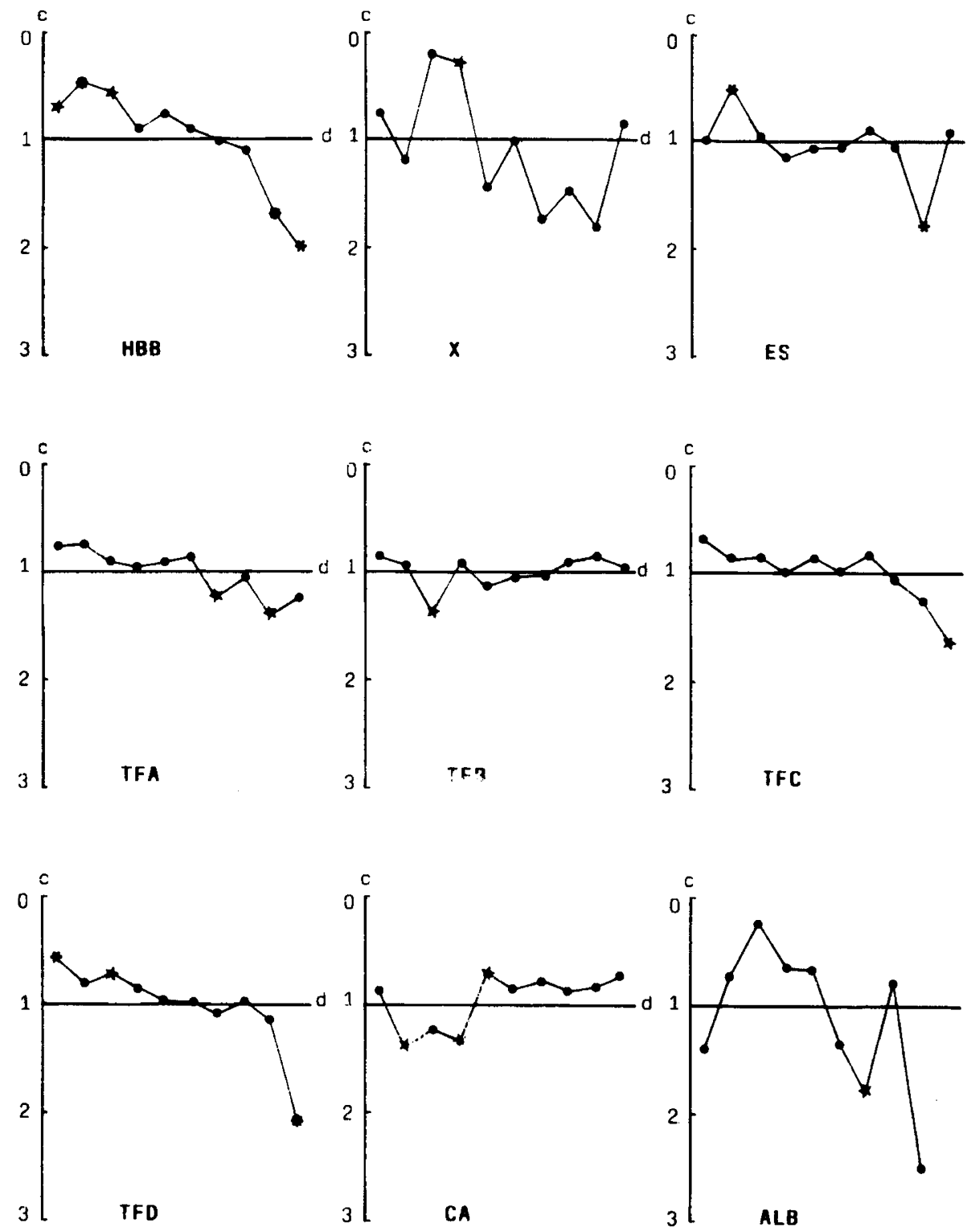

Fig 2. Spatial correlograms of six ovine protein polymorphisms. $c$ : Geary's $c$. The value of the ten distances $(d)$ used were: 434, 732, 977, 1167, 1349, $1546,1754,2032,2417$ and $3082 \mathrm{~km} . \bullet P>0.05, \star P \leqslant 0.05, * P \leqslant 0.01, * P \leqslant 0.001$.

valley and an exterior one along the Mediterranean coast (Ryder 1984). Domestic sheep would have reached Europe and the Iberian peninsula in the 7th and 5th millennia, respectively (Sańchez and Sańchez, 1987). In this way, the HBB and TF 
clines could have originated in isolated founder populations with different genetic constitutions, which emerged in subsequent periods. Since the initial spread of sheep into Europe until the present day migrations would have occurred to a greater or lesser extent between adjacent populations, giving rise to the establishment of clinal patterns. This process is fully compatible with that the theory predicts on the origin of clinal spatial patterns (Endler 1977; Slatkin 1987, 1989). In this way, migration and genetic drift would be the main forces responsible for HBB and TF D spatial gene distribution.

In conclusion, it seems more parsimonious to regard the clines observed at the $\mathrm{HBB}$ and TF loci as due to history (ie, the demographic processes of expansion from the near east of presumably Neolithic animal breeding populations) rather than to geography (ie, adaptation to changing environment). A similar conclusion has been proposed in European cattle (Medjugorac et al, 1994). The generally accepted view whereby human groups dispersed from the near east in the Neolithic, spreading their genes and technologies at the same time (Sokal et al, 1991; Renfrew, 1992; Barbujani and Pilastro, 1993) is in full agreement with this interpretation.

\section{ACKNOWLEDGMENTS}

We thank G Barbujani (Università di Padova, Italy), for many suggestions and critical reading of a previous version of the manuscript.

\section{REFERENCES}

Agar NS, Evans JV, Roberts J (1972) Red blood cell potassium and haemoglobin polymorphism in sheep. A review. Anim Breed Abst 40, 407-436

Altaif KI, Dargie JD (1978) Genetic resistance to helminths. The influence of breed and haemoglobin type on the response of sheep to reinfection with Haemonchus contortus. Parasitology 77, 177-187

Barbujani G (1987) Diversity of some allelic frequencies in European and Asian populations. III. Spatial correlogram analysis. Ann Hum Genet 51, 345-353

Barbujani G, Pilastro A (1993) Genetic evidence on origin and dispersal of human populations speaking languages of the Nostratic macrofamily. Proc Natl Acad Sci USA $91,2757-2761$

Barbujani G, Pilastro A, De Domenico S, Renfrew C (1994) Genetic variation in North Africa and Eurasia: Neolithic demic vs Paleolithic colonisation. Am J Phys Anthropol $95,137-154$

Cavalli-Sforza LL, Bodmer WF (1981) Genética de las poblaciones humanas. Omega, Barcelona, Spain

Easteal S (1985) The ecological genetics introduced populations of the giant toad, Bufo marinus. III. Geographical patterns of variation. Evolution, 39, 1065-1075

Endler JA (1977) Geographic Variation, Speciation and Clines. Princeton University Press, Princeton, NJ, USA

Medjugorac I, Kustermann W, Lazar P, Russ I, Pirchner F (1994) Marker-derived phylogeny of European cattle supports demic expansion of agriculture. Anim Genet $25,19-27$

Morris CA, Jordan TW, Loong PC, Lewis MH, Towers NR (1988) Associations between transferrin type and facial eczema susceptibility and some production traits in sheep. NZ J Agric Res 31, 301-305 
Oden NL (1984) Assessing the significance of a spatial correlogram. Geogr Anal 16, 1-16 Renfrew C (1992) Archaeology, genetics and linguistic diversity. Man 27, 445-478

Ryder ML (1984) Sheep. In: Evolution of Domesticated Animals (Mason IL, ed), Longman, New York, USA, 63-99

Sańchez A, Sańchez MC (1986) Razas ovinas españolas ( $2^{\mathrm{a}}$ ed). Public Ext Agr, MAPA, Madrid, Spain

Slatkin M (1987) Gene flow and the geographic structure of natural populations. Science 236, 787-792

Slatkin M (1989) Population structure and evolutionary progress. Genome 31, 196-202

Sokal RR, Bird J, Riska B (1980) Geographic variation in Pemphigus populicaulis (insecta: Aphididae) in eastern North America. Biol J Linn Soc 14, 163-200

Sokal R, Oden NL (1978) Spatial autocorrelation in biology. I. Methodology. Biol J Linn Soc 10, 199-228

Sokal RR, Oden NL, Wilson C (1991) Genetic evidence for the spread of agriculture in Europe by demic diffusion. Nature 351, 143-145

Wartenberg DE (1989) Spatial Autocorrelation Analysis Program (SAAP). Exeter Software, New York, USA 